\title{
Sinopse dos gêneros de Primulaceae no Brasil
}

\author{
Synopsis of the genera of Primulaceae in Brazil
}

\author{
Maria de Fátima Freitas ${ }^{1,3}$, Tatiana Tavares Carrijo ${ }^{2} \&$ Bruna Nunes de Luna ${ }^{1}$
}

\begin{abstract}
Resumo
Primulaceae é representada no Brasil por 12 gêneros e cerca de 140 espécies. As espécies apresentam hábitos de herbáceo a arbóreo e estão distribuídas nos gêneros Ardisia, Clavija, Ctenardisia, Cybianthus, Geissanthus, Gentlea, Jacquinia, Lysimachia, Myrsine, Parathesis, Samolus e Stylogyne. Esta família é amplamente distribuída no Brasil, sendo que espécies exclusivamente amazônicas pertencem aos gêneros Ctenardisia, Gentlea, e Parathesis. Este estudo apresenta o primeiro registro de Gentlea para o Brasil. É apresentada uma chave de identificação dos gêneros para o Brasil, descrições, ilustrações e comentários com referência dos materiais de herbário analisados.

Palavras-chave: Ericales, Myrsinaceae, taxonomia, Theophrastraceae.

Abstract

Primulaceae is represented by 12 genera and about 140 species in Brazil. Species varies from herbs to trees and are grouped within the genus: Ardisia, Clavija, Ctenardisia, Cybianthus, Geissanthus, Gentlea, Jacquinia, Lysimachia, Myrsine, Parathesis, Samolus, and Stylogyne. The family is widely distributed, but Ctenardisia, Gentlea and Parathesis are exclusively from the Amazonian forests. This study presents the first record of Gentlea in Brazil. An identification key for the Brazilian genera, diagnostics descriptions, illustrations, and comments with reference to herbarium specimens are provided.
\end{abstract}

Key words: Ericales, Myrsinaceae, taxonomy, Theophrastraceaes.

\section{Introdução}

Primulaceae compreende atualmente as subfamílias Maesoideae, Theophrastoideae, Myrsinoideae e Primuloideae (Stevens 2001 onwards). Em sistemas anteriores (Cronquist 1988; APG II 2003) essas subfamílias foram tratadas como famílias independentes (Maesaceae, Theophrastaceae, Myrsinaceae e Primulaceae s.s.) e, por serem estreitamente relacionadas, eram designadas como o "grupo primulóide". Este grupo é caracterizado pelas flores haplostêmones, com corola simpétala, estames opositipétalos, placentação central livre, óvulos bitegmáticos, tenuinucelados e endosperma de formação nuclear (Källersjö et al. 2000).

A significativa alteração, trazida pelas análises moleculares, foi a transferência de gêneros tradicionalmente subordinados à Primulaceae s.s. para Myrsinaceae e Theophrastaceae (Källersjö et al.
2000; Stahl \& Anderberg 2004). Estudos posteriores ampliaram a circunscrição de Primulaceae, que tem prioridade de nome, e subordinaram as demais famílias como subfamílias (APG IV 2016). Na atual fase do conhecimento, apesar das relações entre as subfamílias, cujos gêneros ainda necessitam de maiores esclarecimentos e estudos, Primulaceae s.l. é considerada monofilética (APG IV 2016).

Considerando a circunscrição atual de Primulaceae, são registrados para o Brasil 11 gêneros e 140 espécies (BFG 2015), com ampla distribuição, sendo aqui registrada a primeira ocorrência do gênero Gentlea. Registram-se, portanto, 12 gêneros de Primulaceae para o Brasil. Este trabalho apresenta uma sinopse dos gêneros, com chave para identificação, descrições, comentários taxonômicos e distribuição geográfica, com o propósito de auxiliar na sua identificação e subsidiar projetos futuros.

\footnotetext{
${ }^{1}$ Instituto de Pesquisas Jardim Botânico do Rio de Janeiro, R. Pacheco Leão 915, Jardim Botânico, 22460-030, Rio de Janeiro, RJ, Brasil.

${ }^{2}$ Universidade Federal do Espírito Santo, Centro de Ciências Agrárias, Depto. Biologia, Lab. Botânica, Alto Universitário s/n, Guararema, Alegre, 29500-000, ES, Brasil.

${ }^{3}$ Autor para correspondência: ffreitas@jbrj.gov.br
} 


\section{Material e Métodos}

Este estudo segue as informações contidas na Lista de Espécies da Flora do Brasil (BFG 2015). As descrições da família e dos gêneros foram elaboradas a partir das principais obras de referência para cada táxon, considerando a circunscrição da família configurada pelo APG III (2009), mantida em APG IV (2016), citadas após cada descrição e mencionadas nos comentários. Apresenta-se a descrição da família, e uma chave para os gêneros com espécies que ocorrem no território brasileiro. Para cada gênero é mencionada a obra original, espécie-tipo, descrição com os principais caracteres diagnósticos, ilustração, comentários gerais e um ou mais materiais de referência com a citação de sua localização em coleção de Herbário, cuja sigla segue o Index Herbariorum (Thiers continuamente atualizado). Nos gêneros com circunscrição mais complexa foram acrescidos maiores detalhes na apresentação de suas descrições. O material testemunho da ilustração está incluído na listagem do material selecionado.

\section{Resultados e Discussão}

Primulaceae Batsch ex Borkh., Bot. Wörterb. 2: 240. 1797, nom. cons. Gênero-TIPO: Primula L. - Species Plantarum 1: 142-144. 1753.

Ervas perenes ou anuais, cespitosas a eretas, ou árvores, arbustos; cavidades secretoras presentes em folhas, flores e frutos, ou ausentes. Folhas simples, alternas, rosuladas, subverticiladas, verticiladas ou opostas, pecioladas, subsésseis ou sésseis, sem estípulas; folhas jovens involutas ou conduplicadas. Inflorescências terminais, subterminais ou laterais,paniculadas, racemosas, corimbosas, umbeladas, fasciculadas, ou flores isoladas. Brácteas presentes, precocemente caducas ou ausentes. Flores 3-4-5-meras meras; bissexuais ou unissexuais em plantas dióicas, androdióicas, polígamas ou monóicas; diclamídeas, heteroclamídeas, actinomorfas ou ligeiramente zigomorfas; cálice rotáceo, campanulado, hipocrateriforme; sépalas livres na base ou fusionadas; corola gamopétala, tubo curto ou longo; prefloração contorta, quincuncial ou imbricada; rotata, campanulada, urceolada, hipocrateriforme; lobos oblongos, lanceolados, elípticos ou suborbiculares. Androceu isostêmone ou diplostêmone; estames livres entre si unidos por um tubo estaminal; quando livres entre si são epipétalos ou fusionados à base das pétalas; opositissépalos em uma série, estaminódios, quando presentes, alternissépalos; anteras bitecas, basifixa, introrsa ou extrorsa, deiscentes por poros apicais, fendas longitudinais curtas com ápice alargado, fendas longas, livres entre si ou conadas. Gineceu gamocarpelar, 5 carpelar; ovário súpero ou semi-ínfero, unilocular, placentação central livre, pauciovilado a pluriovulado; óvulos dispostos em uma, duas ou muitas séries na placenta globosa, raramente imersos dentro da placenta, anátropos e bitegmáticos, tenuinucelados; estilete curto ou longo, cilíndrico; estigma punctado, capitado ou truncado. Frutos carnosos, drupas, indeiscentes e monospérmicos, ou frutos secos, cápsulas, deiscentes e polispérmicos; sementes ovóides e lisas, ou angulares e reticuladas ou papilosas; endosperma abundante; embrião reto ou curvo, com cotilédones foliáceos ou pouco diferenciados.

Primulaceae é cosmopolita e ocupa os mais variados ambientes. Possui cerca de 2.590 espécies em 58 gêneros (Stevens 2001 onwards). A família está representada no Brasil por 12 gêneros: Ardisia Sw., Clavija Ruiz \& Pav., Ctenardisia Ducke, Cybianthus Mart. (sensu Agostini 1980), Gentlea Lundell, Geissanthus Hook. f., Lysimachia L. (= Anagallis L.), Jacquinia L., Myrsine L. (incluindo Rapanea Aubl.), Parathesis (A.DC.) Hook. f., Samolous L. e Stylogyne A.DC. (Ståhl 2004a; Ståhl 2004b; Anderberg 2004; Ståhl \& Anderberg 2004), e cerca de 140 espécies (BFG 2015).

Algumas espécies de Ardisia, Primula L., Cyclamen L. e Lysimachia são utilizadas e cultivadas no Brasil como ornamentais (Souza \& Lorenzi 2012). Ardisia compressa Kunth in H.B.K., A. humilis Vahl e A. solanacea Roxb. são arbustos de pequeno porte com frutos vermelhos ou arroxeados muito ornamentais, especialmente interessantes para arborização urbana (Freitas \& Carrijo 2008). Ardisia solanacea, no entanto, ocorrem como subespontânea na Floresta da Tijuca, no estado do Rio de Janeiro (Freitas \& Carrijo 2008), sendo seus frutos provavelmente dispersos por tucanos. Espécies de Jacquinia e Clavija compõem um pequeno grupo economicamente importante: Jacquinia sprucei Mez, ocorrente no Equador e Peru, apresenta raízes e frutos com importância farmacológica, enquanto Clavija nutans (Vell.) B. Ståhl possui flores ornamentais e frutos comestíveis (Stahl 1991, 2004b). 


\section{Chave para identificação dos gêneros de Primulaceae no Brasil}

1. Ervas; fruto cápsula.

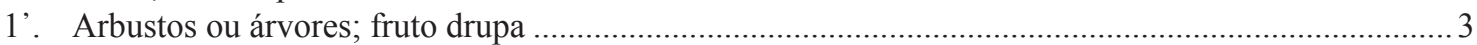

2. Ervas cespitosas; folhas alternas simples ou opostas, ovadas; estaminódio ausente ....Lysimachia

2'. Ervas eretas; folhas alternas em rosetas, espatuladas; estaminódios presentes

3. Folhas pseudoverticiladas; subsésseis; panículas terminais; estaminódios ausentes

3'. Folhas alternas congestas no ápice dos ramos ou distribuídas ao longo dos ramos, pecioladas; racemos ou panículas, laterais ou terminais; estaminódios raramente presentes.

4. Folhas amplas, com margem inteira a geralmente serreada; estaminódios presentes; pericarpo fino, sem cavidades secretoras

4'. Folhas em diversos tamanhos, margem inteira, raro serreada; estaminódios raros; pericarpo espesso, denso em cavidades secretoras visíveis

5. Cálice com sépalas unidas no botão e lobos desiguais...........................eissanthus

5'. Cálice com sépalas livres no botão e lobos iguais

6. Gemas e partes florais com tricomas estrelados e dendróides; corola papilosotomentosa na face interna do tubo da corola....

6'. Gemas e partes florais sem tricomas estrelados e dendróides, ou apenas com tricomas glandulares e tectores unisseriados e plurisseriados; corola glabra ou papilosa na face interna do tubo da corola .

7. Flores bissexuais; corola campanulada; estaminódios petalóides

7'. Flores unissexuais, raro bissexuais; corola rotácea, raro campanulada; sem estaminódios petalóides .

8. Lobos da corola cobertos por tricomas papilosos; filetes inseridos nos lobos da corola. Cybianthus

8'. Lobos da corola glabros, tricomas papilosos na margem ou ausentes; filetes livres ou inseridos no tubo da corola.... 9

9. Inflorescências umbeliformes; corola rotácea; estilete inconspícuo a ausente, estigma morcheliforme..........Myrsine

9'. Inflorescências em panículas ou fascículos; corola campanulada; estilete longo e delgado; estigma puntiforme ou capitado

10. Filetes livres entre si; ovário pauciovulado, com óvulos em uma série Stylogyne

10'. Filetes livres ou unidos entre si; ovário pluriovulado, com óvulos em duas séries ou mais.

.. 11

11. Corola com pétalas róseas ou alvas, contortas no botão, recurvadas na antese, unidas na base; anteras longas sagitadas; pericarpo liso Ardisia

11'. Corola com pétalas esverdeadas a rosadas, imbricadas no botão, não recurvadas na antese, livres na base; anteras curtas ovada-cordadas; pericarpo costado... Gentlea

1. Ardisia Sw., Prodr. [O. P. Swartz] 3: 48. 1788, nom. cons. (Espécie tipo: A tinifolia Sw., Prodr. 3: 48. 1788, typ. cons.).

Fig. 1a-c

Arbustos ou árvores, caule simpodial. Folhas alternas, margem inteira ou denteada, geralmente pontuadas. Inflorescências em panículas terminais, raramente laterais, glabras ou papilosas. Flores pediceladas, bissexuais, 5-meras, raro 4-meras, estivação contorta; cálice glabro ou papiloso, sépalas separadas no botão floral; corola campanulada, actinomorfa, pétalas recurvadas na antese, róseas ou alvas, unidas na base; estames livres entre si 

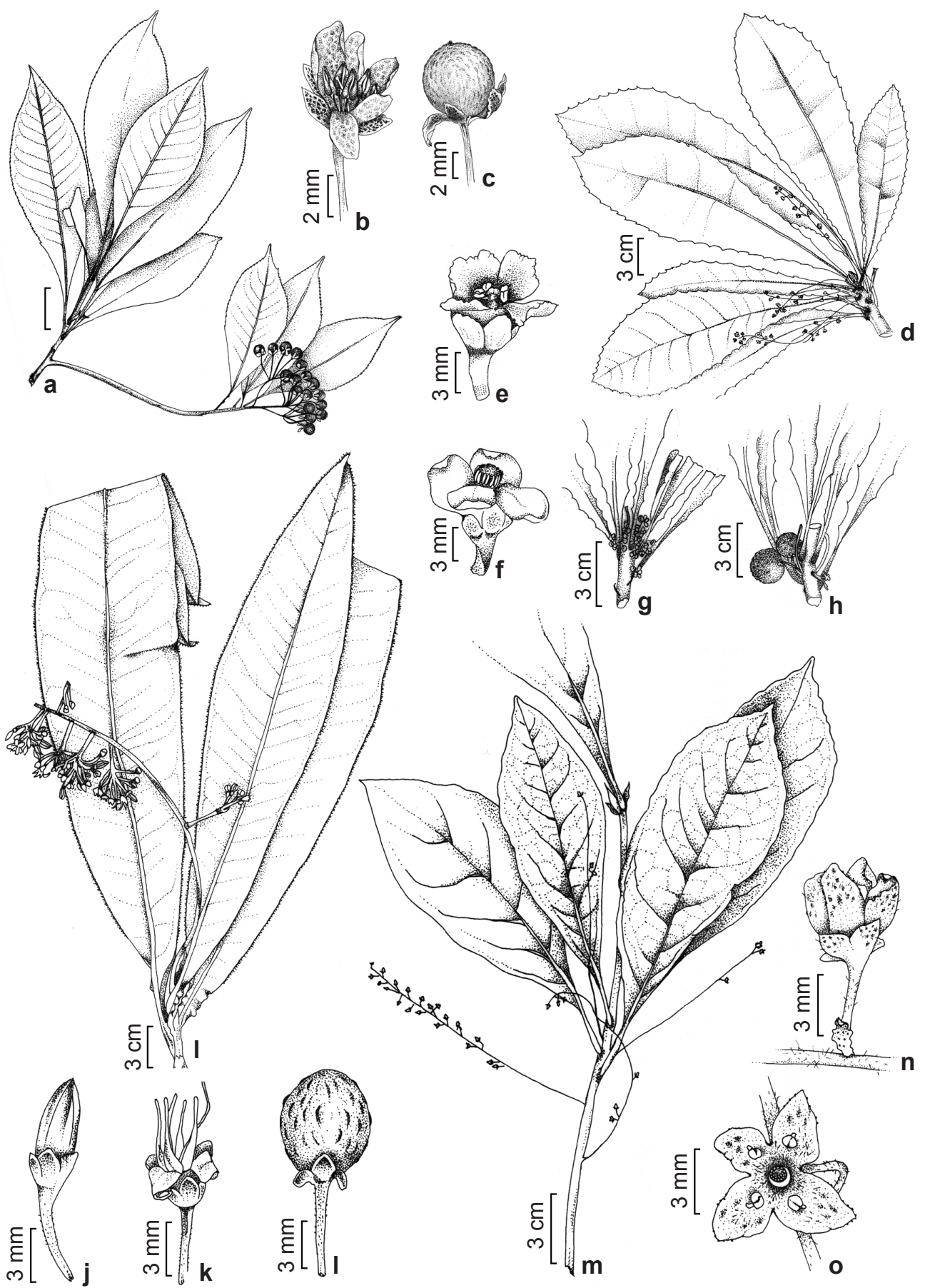
ou unidos por um tubo estaminal, equilongos ou menores que o pistilo, anteras sagitadas, deiscentes por fendas laterais longas ou poricidas; ovário globoso, pluriovulado, óvulos em muitas séries; estilete cilíndrico, estigma capitado. Frutos drupas, monospérmicos, pericarpo liso.

Ardisia é pantropical e abarca 250 espécies (Stahl \& Anderberg 2004) distribuídas predominantemente nos trópicos. Das cinco espécies que ocorrem no Brasil, Ardisia vigoi Lundell, Ardisia guianensis (Aubl.) Mez, Ardisia weberbaueri Mez e Ardisia spruceana Carrijo, M.F. Freitas e Peixoto, são exclusivamente amazônicas, enquanto Ardisia semicrenata Mart. ocorre nas regiões Norte, Nordeste e Sudeste do Brasil.

Compartilha maior similaridade morfológica com os gêneros Parathesis, Ctenardisia e Stylogyne, dos quais se diferencia pelas sépalas com margem glabra (não papilosa como Parathesis) e pelo ovário com óvulos em muitas séries (não pauciovulado como em Ctenardisia e Stylogyne).

A última revisão mundial para Ardisia é a de Mez (1902). Espécies de Ardisia foram citadas e ilustradas em listagens regionais realizadas para os estados do Amazonas (Pipoly 1999) e Acre (Pipoly 2008). Ardisia spruceana foi transferida a partir de Stylogyne, descrita novamente e ilustrada pela primeira vez por Carrijo et al. (2009). Ardisia vigoi é citada na Flora do Acre (Pipoly 2008), cujo espécime tipo tem sua origem no Peru.

Apesar de não ser conhecido uso para as espécies nativas, algumas espécies exóticas são muito apreciadas por paisagistas. Ardisia compressa, A. humilis e $A$. solanacea são arbustos de pequeno porte com frutos vermelhos ou arroxeados muito ornamentais, especialmente interessantes para arborização urbana (Freitas \& Carrijo 2008). Essas mesmas características são encontradas nas espécies nativas de Ardisia, o que reforça seu potencial de uso para este fim.

Material selecionado: Ardisia guianensis (Aubl.) Mez - BRASIL. BAHIA: Ilhéus, Área do Centro de Pesquisas do Cacau, 19.II.1992, fr., S.C. de Sant'Ana et al. 220 (RB, CEPEC). SÃO PAULO: Biritiba-Mirim, Estação Biológica de Boracéia, 14.IX.1984, fl. e fr., $S$. Romaniuc Neto et al. 235 (RB, SPSF). A. semicrenata Mart. - BRASIL. BAHIA: Arataca Serra das Lontras, 12.II.2005, fr., J.G. Jardim 4364 (RB, CEPEC). ESPÍRITO SANTO: Santa Teresa Aparecidinha, 6.X.1998, fl., L. Kolmann et al. 702 (RB, MBML). A. weberbaueri Mez - BRASIL. ACRE: 3.XI.1991, fl., C.A.C. Ferreira 10552 (INPA, NY); Jordão, fr., 5.II.2009, F.A. Michelangeli et al. 1319 (RB, NY).
2. Clavija Ruiz \& Pav., Fl. Peruv. Prodr. 142, tab. 30. 1794. (Espécie-tipo: C. macrocarpa Ruiz \& Pav., Fl. Peruv. 2: 284. 1799.) Fig. 1d-h

Arbustos, caule monopodial, não ramificado ou com poucos ramos próximos ao ápice. Folhas alternas, amplas, geralmente maiores que $15 \mathrm{~cm}$ de comprimento, margem inteira ou geralmente serrada, com ou sem lobos espinescentes, tricomas glandulares inconspícuos. Inflorescências em racemos laterais. Flores pediceladas, uni ou bissexuais, 5 ou 4-meras. Cálice amareloesverdeado, ovados, margem membranosa, ciliada, lobos livres na base; corola laranja a avermelhadas, glabras, textura crassa, lobos fundidos na base, orbiculares. Estames epipétalos, livres ou unidos em um tubo; estaminódios alternos aos lobos da corola, petalóides, obovóides a oblongos. Ovário rudimentar ou ausente em flores estaminadas, ovóides em flores bissexuais e pistiladas, estilete curto. Frutos globosos, drupa, pericarpo fino e polpa amarela a laranja, polispérmico.

Clavija é um gênero da subfamília Theophrastoidea, tribo Theophrasteae, com 50 espécies distribuídas da Nicarágua ao sul do Brasil e centro de diversidade na Colômbia e oeste da Amazônia (Stahl 2004). Das espécies citadas por Miquel (1856), na Flora Brasiliensis, somente C. caloneura Mart., C. lancifolia Desf. e C. macrophylla (Link ex Roem. \& Schult.) Miq. são considerados táxons válidos; $C$. integrifolia Mart. ex Miq. e C. ornata D. Don considerada sinônimos, e C. sparsifolia Miq., um nome excluído na revisão realizada por Stahl (2004). Atualmente são consideradas 10 espécies ocorrentes no Brasil (BFG 2015), com maior diversidade no cerrado e amazônia.

Clavija foi descrito inicialmente sem a citação da espécie. A ilustração da obra original foi baseada em um material identificado por Pavón como $C$. macrocarpa. Esta designação foi apresentada por Stahl (1991), em uma revisão abrangente deste gênero, considerando a ilustração como o seu lectótipo. Posteriormente, Stahl (2004b) apresentou uma breve caracterização morfológica, uma chave e comentários sobre os gêneros de Theophrastaceae (hoje Theophrastoideae, em Primulaceae) como um todo, incluindo os gêneros Clavija e Jaquinia que ocorrem no Brasil.

Material selecionado: Clavija lancifolia (Standl.) B. Stahl - BRASIL. AMAZONAS: Retiro da Serra da Lua, VIII.1913, bt., Kuhlmann (RB 3562). PARÁ: Santarém, 20.VI.2010, fl., M.P. Nascimento 454 (RB, IAN). C. nutans (Vell.) B. Stahl - BRASIL. GOIÁS: prox. Nova 
América, 16.III.1978, fl., J.G. Guimarães 13 (RB). SÃO PAULO: Ribeirão Preto Fazenda Olho D'Água, 20.XII.2006, fr., M. Groppo et al. 1244 (RB, SPFR). C. spinosa (Vell.) Mez - BRASIL. ESPÍRITO SANTO: Vitória, Morro do Vigia, 2.II.1969, fr, D. Sucre et al. 4585 (RB). RIO DE JANEIRO: Cabo Frio, Armação dos Búzios, 2.XI.1983, fl., G. Martinelli et al. 9766 (RB); Restinga de Manguinhos, 12.XI.1999, fl., D. Fernandes et al. 305 (RB).

3. Ctenardisia Ducke, Arch. Jard. Bot. Rio de Janeiro 5: 179. 1930. (Espécie tipo: C. speciosa Ducke. Arch. Jard. Bot. Rio de Janeiro 5: 179. 1930.)

Fig. 1i-1

Árvores, caule monopodial. Folhas subverticiladas, no ápice do caule, margem inteira ou denteada, pontuadas, subsésseis. Inflorescências em panículas terminais, glabras. Flores pediceladas, bissexuais, 5-meras, estivação contorta; cálice glabro, sépalas separadas no botão floral; corola campanulada, actinomorfa; estames livres entre si, pouco menores que o pistilo; estaminódios ausentes; anteras deiscentes por fendas laterais longas; ovário globoso, pauciovulado, óvulos em uma série; estilete cilíndrico, estigma puntiforme. Fruto drupa, monospérmico.

Ctenardisia é neotropical, com 5 espécies distribuídas da América Central ao norte da América do Sul. As duas espécies que ocorrem no Brasil, C. speciosa e C. stenobotrys (Standl.) Lundell \& Pipoly são exclusivamente amazônicas, ocorrendo nos estados do Pará e Amazonas, respectivamente (BFG 2015). A presença de flores róseas e frutos arroxeados e lustrosos assemelhamse àqueles de Ardisia humilis e A. solanacea, o que reforça o potencial dessas espécies ao uso no paisagismo.

Ctenardisia é afim à Ardisia, principalmente pelas flores campanuladas e róseas. No entanto, pode ser facilmente diferenciado pela disposição dos óvulos em uma série (em Ardisia os óvulos estão dispostos em várias séries). As duas espécies de Ctenardisia que ocorrem no Brasil apresentam inflorescências paniculadas bastante singulares, nas quais conjuntos de ramos florígenos umbelados estão dispostos em um pedúnculo alongado. Outra característica de Ctenardisia é que, o caule com crescimento monopodial e folhas adensadas no ápice, assemelha-se ao observado em Clavija e em algumas espécies de Cybianthus.

A bibliografia que trata de espécies deste gênero do Brasil está representada pela obra original do gênero (Ducke 1930), que descreve a espécie típica (C. speciosa) e a combinação $C$. stenobotrys, a partir de Ardisia (Lundell 1982). Não há revisão para Ctenardisia.

Material selecionado: Ctenardisia speciosa Ducke - BRASIL. PARÁ: Lago Salgado (Rio Trombetas), 7.II.1927, fl., Ducke (RB 2524). C. stenobotrys (Standl.) Lundell \& Pipoly - BRASIL. AMAZONAS: Rio Maturacá, abaixo do Salto de Huá, 10.XII.1930, S.F. Blake et al. 521 (MO, NHM).

4. Cybianthus Mart., Nov. Gen. Sp. Pl. 3: 87. 1831. (Espécie-tipo: C. penduliflorus Mart., Nov. Gen. Sp. P1. 3: 87, t. 236, 1831). $\quad$ Fig. 1m-o; 2a-b

Arbustos a árvores, ramificados, caule monopodial em arbustos de menor porte. Folhas alternas a subverticiladas, ao longo dos ramos, margem inteira, densamente pontuadas, pilosidade densa a folhas glabras, geralmente discolores. Inflorescências em racemos e panículas laterais ou terminais, glabras a pilosas. Flores pediceladas a sésseis, dióicas, 4-5 meras; corola com lobos patentes a eretos, curtamente campanulada, actinomorfa, ovados, com densos tricomas glandulares na face interna; cálice glabro a piloso na margem, lobos em mesmo número que as pétalas; anteras globosas, deiscentes por fendas curtas a longas, filetes curtos, inseridos no lobo da corola; ovário globoso, estigma capitado a puntiforme. Frutos globosos, drupas, monospérmicos.

Cybianthus é um dos maiores gêneros de Primulaceae com cerca de 150 espécies de distribuição nos neotrópicos (Stahl \& Anderberg, 2004). No Brasil ocorrem cerca de 66 espécies (BFG 2015).

A maior contribuição na classificação geral de Cybianthus, após Mez (1902) foi realizada por Agostini (1980). Nesta revisão, baseada em Miquel (1856) e Mez (1902), as espécies foram distribuídas em 10 subgêneros. Pipoly (1987) restabeleceu posteriormente o gênero Grammadenia, incluído por Agostini (1980) em Cybianthus, como um subgênero deste, em virtude das espécies analisadas em seu tratamento taxonômico. Com isso, perfazem 11 subgêneros. No Brasil, as espécies conhecidas estão distribuídas nos subgêneros: Conomorpha (A. DC.) G. Agostini, Cybianthus, Laxiflorus G. Agostini e Weilgetia (A.DC.) G. Agostini Os demais subgêneros são: Comomyrsine (Hook f.) G. Agostini, Cybianthopsis (Mez) G. Agostini, Grammadenia (Benth) Pipoly, Iteoides G. Agostini, Micronomorpha (Mez) G. Agostini, Stapfia G. Agostini e Triadophora (Mez) G. Agostini (Agostini, 1980).

O conhecimento deste gênero baseia-se no conhecimento de floras regionais de alguns 


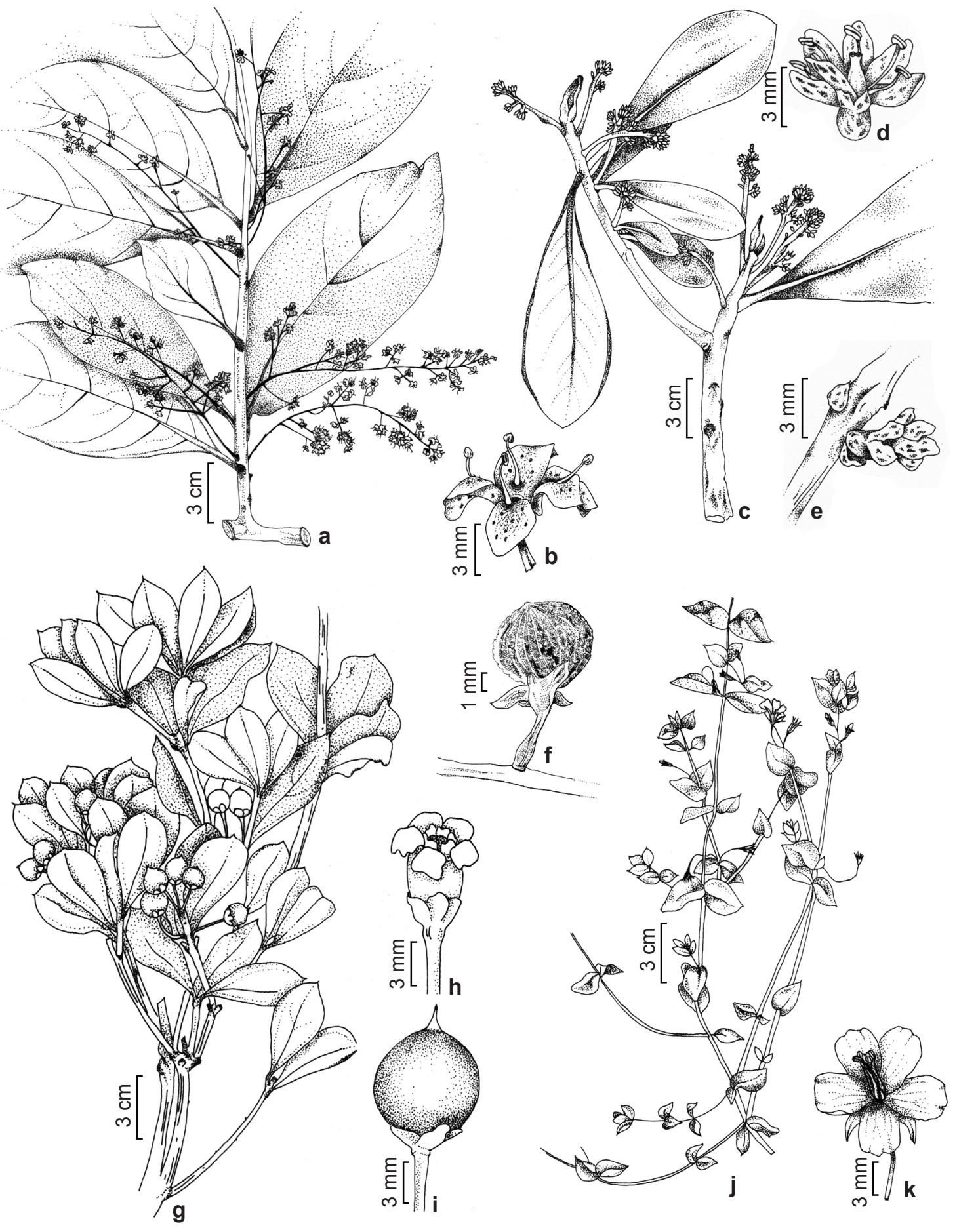

Figura 2 - a-b. Cybianthus oblongifolius - a. ramo com flores; b. flor estaminada. c-e. Geissanthus quindiensis c. ramo com flores; d. flor; e. detalhe do ramo com flor. f. Gentlea venosissima - detalhe do fruto. g-i. Jacquinia armillaris - g. ramo com frutos; h. flor; i. fruto. j-k. Lysimachia arvensis - j. ramo com flores; k. flor. (a-b. Jardim 2778; c-e. Farney 846; f. Ratter 5850; g-i. Oliveira 154; h. Bovini 1927; j-k. Barros 451)

Figure 2 - a-b. Cybianthus oblongifolius - a. branch with flowers; b. staminate flower. c-e. Geissanthus quindiensis - c. branch with flowers; d. flower; e. detail of branch with flower. f. Gentlea venosissima - fruit. g-i. Jacquinia armillaris - g. branch with fruits; h. flower; i. fruit. j-k. Lysimachia arvensis - j. branch with flowers; k. flower. (a-b. Jardim 2778; c-e. Farney 846; f. Ratter 5850; g-i. Oliveira 154; h. Bovini 1927; j-k. Barros 451) 
subgêneros, revisão de subgêneros com pequeno número de espécies e a publicação de espécies novas por Pipoly (1981, 1983a, 1983b, 1987, 1988, 1991, 1992, 1993, 1994, 1996, 1998). Algumas espécies de Cybianthus que ocorrem no Brasil vêm sendo descritas em floras regionais, locais ou em outros países latino-americanos, que contribuem com o acréscimo de informações morfológicas e de distribuição (Harvey \& Pipoly 1995; JungMendaçolli et al. 1997; Pipoly 1998; Freitas \& Carrijo 2008; Freitas et al. 2009; Jung-Mendaçolli 2009). Ocorre em formações de Mata Atlântica e Cerrado, especialmente em áreas de sub-bosque que estejam bem preservadas. Porém, a maior diversidade é destacada nas formações vegetais da Amazônia (BFG 2015), conhecidas especialmente pelas contribuições de Pipoly $(1999,2008)$ para a Flora da Reserva Ducke, estado do Amazonas, e Flora do Acre, respectivamente. A descrição mais recente de C. membranaceus Jung-Mend., Bernacci \& M. F. Freitas na Floresta Atlântica (Jung-Mendaçolli et al. 2010) e a redescoberta de C. froelichii Mez (Freitas et al. 2016), demonstram o quanto ainda é preciso ser investigado, mesmo sendo este um gênero bem conhecido que apresenta tratamento taxonômico das espécies que ocorrem fora do Brasil. Apesar disso, importa destacar que a principal obra utilizada para identificação das espécies ainda se trata da monografia de Mez (1902), seguida das obras supra-citadas.

Material selecionado: Cybianthus brasiliensis (Mez) G.Agostini - BRASIL. BAHIA: Arataca, Serra do Peito de Moça, 19.XI.2010, fr., L. Daneu et al. 448 (RB, CEPEC). MINAS GERAIS: Lima Duarte, Parque Estadual de Ibitipoca, 15.IV.2014, fl., R. Marquete et al. 4415 (RB). SANTA CATARINA: Benedito Novo, 29.III.2010, fr., J.L. Schmitt et al. 1780 (RB, FURB). C. densicomus Mart. - BRASIL. SÃO PAULO: Itirapina, 29.VIII.1985, fl., O. Cesar et al. 604 (IAC, RB). C. detergens Mart. BRASIL. DISTRITO FEDERAL: Reserva Ecológica do IBGE, 2.X.1983, fl., R. C. Mendonça 250 (RB). MINAS GERAIS: Santa do Riacho, 27.IX.2002, fl., K. Yamamoto et al. 48 (RB). C. oblongifolius (A. DC.) G. Agostini BRASIL. BAHIA: Nilo Peçanha, 23.II.2000, J.G. Jardim et al. 2778 (CEPEC).

5. Geissanthus Hook. f. in Benth. \& Hook. f., Gen. Pl. 2(2): 642. 1876. (Espécie-tipo: G. bolivianus Britton, Bull. Torrey Bot. Club 20(4): 140. 1893.

Fig. 2c-e

Arbustos ou árvores, caule simpodial. Folhas alternas, margem inteira ou serreada, pontuadas ou não. Inflorescências em panículas terminais, glabras ou papilosas. Flores pediceladas, unissexuais (plantas dióicas ou polígamas), 5-meras, estivação imbricada; cálice glabro ou papiloso, sépalas completamente ou parcialmente unidas no botão floral; corola campanulada, actinomorfa; estames livres entre si, menores, equilongos ou maiores que o pistilo, nesse caso, excertos pelos filetes longos, anteras deiscentes por fendas laterais longas; ovário globoso, 3-5 óvulos, em uma série; estilete cilíndrico, estigma capitado. Frutos drupa, monospérmicos.

Geissanthus é exclusivamente neotropical e abarca 30 espécies (Stahl \& Anderberg 2004). Duas espécies ocorrem no Brasil, sendo que uma é restrita à Floresta Amazônica (Geissanthus quindiensis Mez), e a outra (Geissanthus ambiguus (Mart.) G. Agostini) distribui-se continuamente do Amazonas ao Pará, passando pela região Centro-Oeste do Brasil (Cerrado) até chegar à Floresta Atlântica dos estados de São Paulo e Minas Gerais.

Este gênero compartilha maior similaridade morfológica com Stylogyne, do qual se diferencia facilmente pelas sépalas total ou parcialmente unidas no botão floral.

Não há revisões recentes para Geissanthus, sendo aquela apresentada por Mez (1902) a última realizada para o gênero. Geissanthus ambiguus foi descrita como Ardisia ambigua Mart. em listagens regionais para o estado de São Paulo (JungMendaçolli et al. 2005) e sinopses taxonômicas para as espécies do Brasil (Bernacci \& JungMendaçolli 2001).

Material selecionado: Geissanthus ambiguus (Mart.) G. Agostini - BRASIL. GOIÁS: $6 \mathrm{~km}$ ao NE de Goiás, 12.II.1980, J.H. Kirkbride Junior 3432 (UB). SÃO PAULO: Bauru, 2.XII.1996, M.H.O. Pinheiro 259 (FUEL). RONDÔNIA: 14.VI.1984, fl., C.A. Cid et al. 4509 (INPA). G. quindiensis Mez BRASIL. AMAZONAS: 19.VIII.1985, fl., C. Farney et al. 846 (RB).

6. Gentlea Lundell, Wrightia 3(6): 100. 1964. (Espécie-tipo: G. venosissima (Ruiz \& Pav.) Lundell, Wrightia 3(6): 103. 1964)

Fig. $2 \mathrm{f}$

Arbustos a arvoretas, caule simpodial. Folhas alternas, margem inteira ou denteada, geralmente pontuadas. Inflorescências em panículas terminais ou umbelas. Flores pediceladas, bissexuais, 5-meras, estivação imbricada; campanulada ou rotácea, actinomorfa, pétalas não recurvadas, esverdeadas a rosadas; estames livres entre si ou unidos por um tubo estaminal, anteras ovadas-cordadas, deiscentes por fendas laterais; ovário globoso, plurivovulado, óvulos em duas ou muitas séries; estilete cilíndrico, estigma capitado. Frutos drupa, monospérmicos, pericarpo costado. 
Gentlea é exclusivamente neotropical, com 9 espécies ocorrentes do México ao Peru (Ricketson \& Pipoly 1997a). O presente estudo aponta uma primeira ocorrência deste gênero no Brasil, a partir da análise das coleções do Herbário INPA. Apesar da circunscrição genérica na subfamília Myrsinoideae ser bastante complexa, especialmente em se tratando dos gêneros Ardisia e Stylogyne que são os mais próximos morfologicamente de Gentlea, foi possível identificar esta nova ocorrência considerando as descrições de Ricketson \& Pipoly (1997a), principalmente quanto a morfologia dos frutos, cujo pericarpo costado o diferencia dos demais gêneros (figura 2F). A descrição das estruturas florais segue as obras de Ricketson \& Pipoly (1997a) e Sthal \& Anderberg (2004). A presente ocorrência atesta a necessidade dos estudos da família Primulaceae na flora amazônica.

Material selecionado: Gentlea venosissima (Ruiz \& Pavon) Lundell - BRASIL. RORAIMA: 27.III.1987, fr., J.A. Ratter et al. 5850 (INPA, RB)

7. Jacquinia L., Fl. Jamaic. 27. 1759. (Espécietipo: J. ruscifolia Jacq., Enum. Syst. Pl., 15. 1760)

Fig. $2 g-i$

Arbustos, caule ramificado. Folhas alternas, coriáceas, margem inteira e ápice geralmente apiculado, pontuadas. Inflorescências em racemos terminais, glabras. Flores longopediceladas, bissexuais, 5-meras; corola campanulada, com apêndices petalóides; estames unidos na base pelos filetes, excertos, anteras deiscentes por fendas laterais; ovário globoso, estilete curto, estigma capitado, persistentes no fruto. Fruto globoso, drupa, monospérmico.

Jacquinia apresenta 32 espécies distribuídas nas Antilhas, América Central e América do Sul (Stahl 2004). Na costa brasileira ocorre apenas Jacquinia armillaris Jacq. (Stahl 1992). Mez (1902) descreveu como Jacquinia brasiliensis Mez as espécies do leste brasileiro disjuntas das demais regiões da América do Sul. Baseado em caracteres morfológicos pouco distintos e na análise da distribuição geográfica, Stahl (1992) a tratou como $J$. armillaris.

Revisões taxonômicas do gênero, antes descrito na família Theophrastaceae, foram realizadas por Stahl $(1989,1995)$.

Material selecionado: Jacquinia armillaris Jacq. BRASIL. BAHIA: Porto Seguro, 4.VI.1980, fr., L.A. Mattos Silva et al. 848 (RB, CEPEC). ESPÍRITO SANTO: Vila Velha, 21.XII.1980, fl., B. Weinberg 128 (RB). PERNAMBUCO: Ilha de Santo Aleixo,
28.III.2013, fr., L.R. Silva 370 (RB, HST). RIO DE JANEIRO: Armação dos Búzios, 28.V.2000, fr., $A$. Oliveira et al. 154 (RB); Rio das Ostras, 18.XII.2000, fl., M. Bovini et al. 1927 (RB).

8. Lysimachia L., Sp. Pl. 1: 146. 1753. (Espécietipo: L. vulgaris L., Sp. Pl. 1: 146. 1753)

Fig. $2 \mathrm{j}-\mathrm{k}$

Ervas cespitosas, anuais, bianuais ou perenes, folhas opostas, raro alternas, ovadas a lineares, inteiras. Flores solitárias ou em racemos terminais, bissexuais, 5-meras; corola rotácea ou campanulada; estames livres, filetes geralmente pilosos, estigma capitado, persistente no fruto. Fruto globoso, capsular, com numerosas sementes.

Lysimachia apresenta cerca de 170 espécies (incluindo os sinônimos designados por Manns \& Anderberg 2005), com ampla distribuição no mundo (Stahl \& Anderberg 2004). No Brasil ocorrem 7 espécies, que originalmente foram descritas no gênero Anagallis L. (Taylor 1955; Garcia \& Izumisawa2003; BFG 2015).

As similaridades morfológicas entre Anagallis e Lysimachia, diferenciados apenas pela forma de deiscência da cápsula e coloração da corola, foram alvo de muitas discussões sobre estes gêneros (Anderberg \& Stahl 1995). As análises morfológicas e moleculares de genes de cloroplastos realizadas por Kallersjo et al. (2000) apontaram o parafiletimo do gênero Lysimachia.

Novos estudos, ampliados pelas análises morfológicas e por diferentes genomas, incluindo outros gêneros relacionados a Lysimachia (Anderberg et al. 2007; Manns \& Anderberg 2005,2007 ), corroboraram para uma nova circunscrição e o estabelecimento de novas combinações e sinônimos. Estes incluem as espécies de Anagallis L., Centunculus L., Glaux L., Trientalis L., Asterolinon Hoffmanns \& Link e Pelletiera A. St.-Hil. (Manns \& Anderberg 2009). Todos esses gêneros foram descritos originalmente em Primulaceae, e posteriormente foram inseridos em Myrsinaceae. (APG II 2003, Stahl \& Anderberg 2004).

Material selecionado: Lysimachia arvensis (L.) U. Manns \& Anderb. - BRASIL. MINAS GERAIS: Caldas, Área de Proteção Ambiental da Pedra Branca, 9.X.2013, fl., J.P.L. Braga 187 (RB, AFR). RIO GRANDE DO SUL: São Francisco de Paula, 29.I.1985, fl., E. Guimarães 1541 (RB). SÃO PAULO: São Paulo, Jardim São Francisco, 22.IX.1990, fl., A.A.M. de Barros et al. 451 (RB). L. filiformis (Cham. \& Schltdl.) U. Manns \& Anderb. - BRASIL. RIO 
DE JANEIRO: Itatiaia, 7.I.1947, Duarte 854 (RB). SANTA CATARINA: Santa Cecília, 2.I.1962, fl., $R$. Reitz 11373 (RB). L. minima (L.) U. Manns \& Anderb. - BRASIL. PERNAMBUCO: Caruaru, Inselberg Pedra do Guariba, 23.IX.2007, fr., P. Gomes et al. 574 (RB, UFP). L. tenella L. - BRASIL. PARANÁ: Ponta Grossa, 13.I.1886, fl., P. Schwacke 2809 (RB).

9. Myrsine L. Sp. Pl. 1 (1): 196. 1753. (Espécietipo: M. africana L., Sp. Pl. 1 (1): 196. 1753)

Fig. 3a-e

Arbustos ou árvores, dióicos, caule monopodial. Folhas alternas, pontuadas. Inflorescências umbeliformes ao longo dos ramos terminais, raro pequenos racemos. Flores pediceladas unissexuais, 4-5(6) meras; cálice glabro, margem geralmente piloso, lobos triangulares, com pontuações nigrescentes a amareladas, globosas, corola, rotácea, raro campanulada, actinomorfa, glabra com margem papilosa; estames, das flores estaminadas, e estaminódios, das flores pistiladas, unidos entre si por tubo estaminal aderido ou parcialmente livre do tubo da corola, filetes com porção livre na região de inserção com a antera ou inconspícuo; estames menores que as pétalas, oblongos, estaminódios sagitados, basifixos, deiscentes por fendas laterais; ovário e pistilódio globosos, placenta globosa, óvulos 3-4 unisseriados; estilete inconspícuo a ausente; estigma longo, cônico, fimbriado, reduzido no pistilódio. Frutos drupa, monospérmico, globosos a elípticos com cálice persistente.

Myrsine é um dos gêneros mais diversos da família no Brasil com 26 espécies (Freitas \& Carrijo 2015; BFG 2015). Recentemente foi publicado um tratamento taxonômico para o gênero nas regiões sudeste e sul do Brasil, que apresenta chaves, descrições e ilustrações das espécies conhecidas (Freitas \& Kinoshita 2015). Material selecionado: Myrsine congesta ( $\mathrm{Sw}$.) Pipoly - BRASIL. MINAS GERAIS: Santana do Riacho, 15.VIII.1979, fl., A.M. Giulietti CFSC 5629 (RB, SPF). M. gardneriana A. DC. - BRASIL. RIO DE JANEIRO: Teresópolis, Parque Nacional da Serra dos Órgãos, 10.IV.2014, fl., M.F. Freitas 415 (RB). M. parvifolia A.DC. - BRASIL. SANTA CATARINA: Laguna Praia da Teresa, 15.III.2005, fr., G. Hatschbach 79615 (RB, MBM). M. umbellata Mart. - BRASIL. MINAS GERAIS: Poços de Caldas, 11.XII.2001, fr., C.N. Fraga et al. 812 (RB). PARANÁ: Ibiporã Fazenda Doralice, 3.VIII.1994, fl., F.C. e Silva et al. 1724 (RB). SÃO PAULO: São Carlos, 10.VI.2008, fl., P. Novaes (RB 484476). M. villosissima Mart. - BRASIL. MINAS GERAIS: Ouro
Preto, APA Andorinhas, Camarinhas, 1.VII.2014, fr., M.F. Freitas et al. 451 (RB).

10. Parathesis (A.DC.) Hook. f., Gen. Pl. 2(2): 645. 1876. (Espécie-tipo: P. serrulata (Sw.) Mez, Symb. Antill. 2(3): 403-405. 1901) Fig. 3f-g

Arbustos ou árvores, caule simpodial, tricomas estrelados nos ramos jovens e gemas. Folhas alternas, geralmente pontuadas. Inflorescências em panículas terminais e laterais, coberta por indumento tomentoso. Flores pediceladas, bissexuais, 5 meras, prefloração contorta; cálice geralmente coberto por tricomas estrelados, sépalas separadas no botão floral; corola campanulada, actinomorfa; estames livres entre si, equilongos ou pouco menores que o pistilo; anteras deiscentes por fendas laterais longas; ovário globoso, 4-7 óvulos em uma série; estilete cilíndrico, estigma capitado. Fruto drupa, monospérmico.

Parathesis é exclusivamente neotropical e abarca 70 espécies (Ricketson \& Pipoly 2010). Está representado no Brasil por $P$. amazonica $\mathrm{Mez}$, de ocorrência nos estados do Acre e Amazonas, e por Parathesis palaciosii Pipoly, de ocorrência nos estados do Acre e Rondônia.

Compartilha maior similaridade morfológica com Ardisia, principalmente pelas diminutas flores róseas campanuladas, mas diferencia-se pela disposição dos óvulos no ovário em uma série. Esta espécie destaca-se em Parathesis por apresentar indumento tomentoso de coloração avermelhada que cobre as inflorescências. Este indumento, em material herborizado, assume coloração ferrugínea.

Após Mez (1902), uma revisão completa para Parathesis foi apresentada por Lundell (1966). Outra citação para a espécie no Brasil consta na Flora do Acre (Daly \& Silveira 2008).

Material selecionado: Parathesis amazonica Mez BRASIL. AMAZONAS: Humaitá, 14.IX.1934, fr, B.A. Krukoff 6293 (RB); P. palaciosi Pipoly - BRASIL. RONDÔNIA: 16.VI.1984, fr., C.A. Cid et al. 4592 (INPA).

11. Samolus L. Sp. Pl. 1: 171. 1753. (Espécie-tipo: S. valerandi L., Sp. Pl. 1: 171-172. 1753.

Fig. 3h-j

Ervas eretas, com folhas alternas em rosetas, cavidades secretoras raras, esparsas, com tricomas glandulares, subsésseis a sésseis, espatuladas. Inflorescências em racemos ou corimbos, uma bráctea presente ou ausente. Flores com pedicelos longos, bissexuais, 5 meras, prefloração imbricada; cálice persistente, parcialmente soldado no ovário; corola campanulada a urceolada; estamos inclusos, 

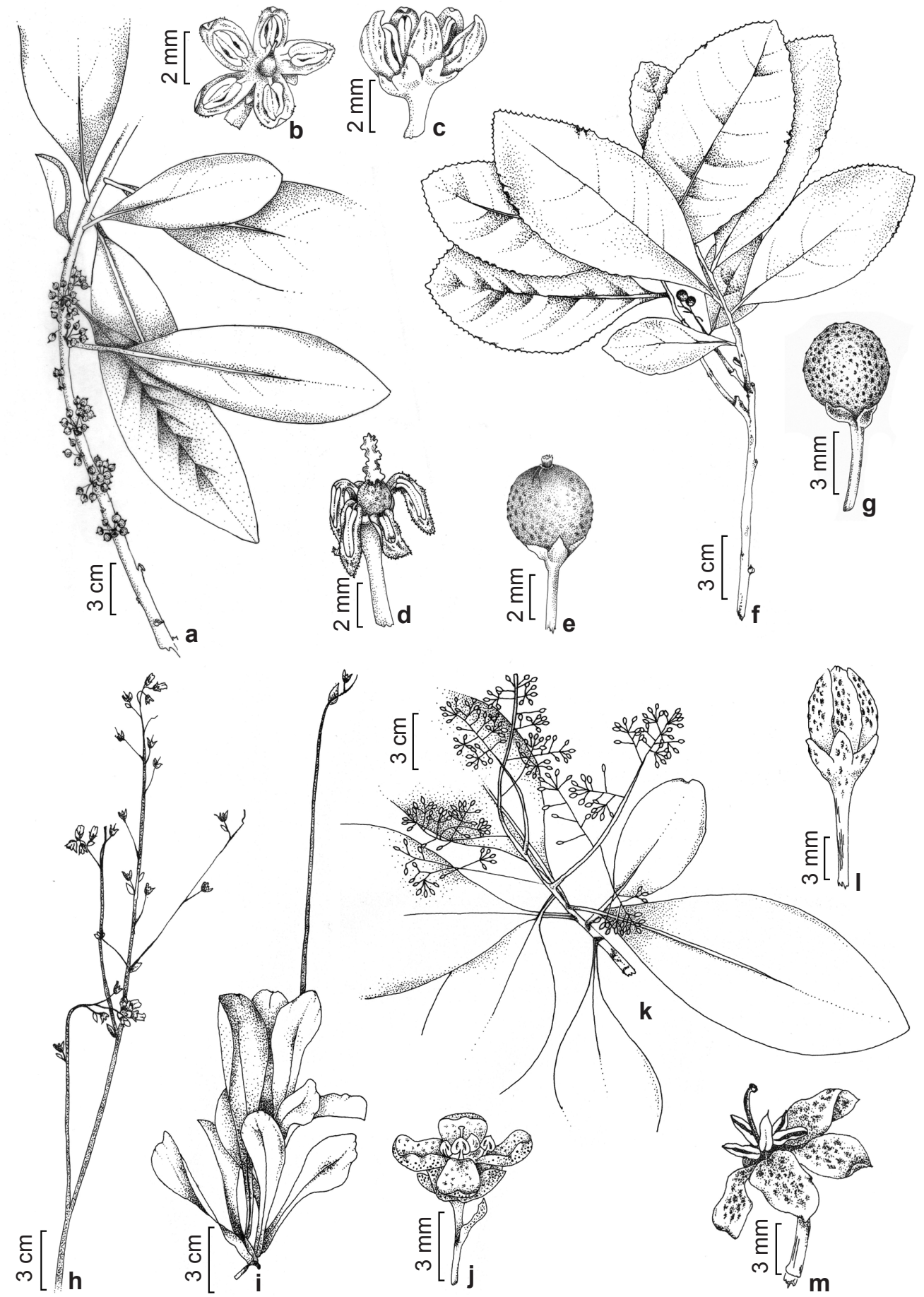

Figura 3 - a-e. Myrsine umbellata - a. ramo com frutos; b-c. flor estaminada; d. flor pistilada; e. fruto. f-g. Parathesis amazonica - f. ramo com frutos; g. fruto. h-j. Samolus subnudicaulis - h. detalhe do ramo com flores; i. ramo com flores; j. flor. k-m. Stylogyne laevigata - k. ramo com botões; 1. botão floral; m. flor. (a, e. Fraga 812, b, c. Novaes (RB 48476); d. Chagas e Silva 1724; f,g. Krukoff 6293; h-j. Sello (RB 135707); k-1. Giordano 2026; m. Occhioni 705).

Figure 3 - a-e. Myrsine umbellata - a. branch with fruits; b-c. staminate flower; d. pistillate flower; e. fruit. f-g. Parathesis amazonica - f. branch with fruits; g. fruit. h-j. Samolus subnudicaulis - h. detail of branch with flowers; i. branch with flowers; j. flower. k-m. Stylogyne laevigata - k. branch with flower buds; 1. flower bud; m. flower. (a, e. Fraga 812, b,c. Novaes (RB 48476); d. Chagas e Silva 1724; f,g. Krukoff 6293; h-j. Sello (RB 135707); k-1. Giordano 2026; m. Occhioni 705). 
raro excertos; filetes unidos ao tubo da corola, anteras sagitadas a oblongas, rimosas; estaminódios petalóides, alternos aos lobos da corola; ovário semi-ínfero; estilete longo, estigma capitado; óvulos em muitas séries. Fruto cápsula globosa, loculicida.

Samolus apresenta 12 espécies, sendo uma cosmopolita ( $S$. valerandii L.) e as demais restritas ao Hemisfério Sul (Wanntorp \& Anderberg 2011). As diversas controvérsias sobre o posicionamento dos gêneros de Primulaceae são evidentes em Samolus, que pelas diversas afinidades morfológicas é tradicionalmente tratado nesta família (Wanntorp \& Anderberg 2011). Porém, as análises de filogenia molecular realizadas por Kallersjo et al. (2000) o inseriram em Theophrastaceae. Das espécies deste gênero, somente $S$. valerandii é conhecida por sua importância econômica, popularmente utilizada em aquários (Stahl 2004a).

Material selecionado: Samolus valerandi L. - BRASIL. RIO GRANDE DO SUL: Uruguaiana, IX.1984, fl., M. Sobral 3354 (INPA). S. subnudicaulis A.St.-Hil. BRASIL. RIO GRANDE DO SUL: s.d., fl., Sello (RB 135707).

12. Stylogyne A.DC., Ann. Sci. Nat., Bot., sér. 2, 16: 78,91. 1841. (Espécie-tipo: S. martiana A. DC., Ann. Sci. Nat., Bot., sér. 2, 16: 91. 1841)

Fig. 3k-m

Arbustos ou árvores, caule simpodial. Folhas alternas, geralmente pontuadas. Inflorescências em panículas, corimbos ou fascículos, raramente racemos duplos, terminais, subterminais ou axilares, glabras ou papilosas. Flores pediceladas, bissexuais ou unissexuais (plantas dióicas, androdióicas ou polígamas), 4-5 meras, prefloração contorta; cálice glabro, raramente papiloso, sépalas separadas no botão floral; corola campanulada, actinomorfa; estames livres entre si, equilongos ou maiores que o pistilódio nas flores estaminadas, equilongos nas flores bissexuais e pistiladas; anteras deiscentes por fendas laterais longas, ou por fendas laterais curtas com ápice dilatado; ovário globoso, 3-5(6) óvulos em uma série; estilete cilíndrico, estigma capitado; pistilódio ausente, ou obturbinado, ou semelhante ao pistilo, porém com menor tamanho. Fruto drupa, monospérmico.

Stylogyne é exclusivamente neotropical e abarca 35 espécies (Ricketson \& Pipoly 2010). Está representado por 18 espécies no Brasil, ocorrentes exclusivamente nas Florestas Amazônica e Atlântica (Carrijo et al. 2012). Além da revisão taxonômica realizada para Stylogyne no Brasil
(Carrijo et al. 2012), outros estudos foram realizados especificamente para o gênero na Floresta Atlântica como a descrição de novas espécies (Carrijo \& Freitas 2009; Carrijo et al. 2011a), e para a Flora do estado do Rio de Janeiro (Carrijo \& Freitas 2008).

Listagens regionais para a família Primulaceae que igualmente somaram informações para Stylogyne no Brasil foram realizadas para os estados do Amazonas (Ribeiro et al. 1999), Acre (Daly et al. 2008), Minas Gerais (Oliveira-Filho 2006), Rio de Janeiro (Jung-Mendaçolli \& Bernacci 2001, Freitas \& Carrijo 2008) e São Paulo (JungMendaçolli et al. 2005).

Material selecionado: Stylogyne atra Mez - BRASIL. AMAZONAS: Manaus, 23.XI.2007, fl., T.T. Carrijo et al. 1221 (RB). S. laevigata (Miq.) Mez - BRASIL. RIO DE JANEIRO: Paraty, Córrego dos Micos, 23.VIII.1995, fl., L.C.S. Giordano et al. 2026 (RB); Rio de Janeiro, Mata da Gávea, 20.IX.1946, fl., P. Occhioni et al. 705 (RB).

\section{Agradecimentos}

À Fundação de Amparo a Pesquisas do Estado do Rio de Janeiro (FAPERJ), o auxílio recebido para pesquisas realizadas na família Primulaceae; aos curadores dos herbários consultados e aos revisores do texto. Às ilustradoras Alice Ribeiro e Ângela Deise, alunas do curso de Ilustração Botânica da Escola Nacional de Botânica Tropical (JBRJ), a confecção das ilustrações.

\section{Referências}

Agostini, G. 1980. Una nueva clasificación del género Cybianthus (Myrsinaceae). Acta Botanica Venezuelica 10: 129-185.

Anderberg, A.A. 2004. Primulaceae. In: Kubtzki, K. (ed). The families and genera of vascular plants, VI. Flowering Plants Dicotyledons. Celastrales, Oxalidales, Rosales, Cornales, Ericales. Springer, Berlin. Pp. 313-319.

Anderberg, A.A. \& Stahl, B. 1995. Phylogenetic interrelationships in the order Primulales, with special emphasis on the family circumscriptions. Canadian Journal of Botany 73:1699-1730.

Anderberg, A.A.; Stahl, B. \& Kallersjo, M. 1998. Phylogenetic relationships in the Primulales inferred from $r b c \mathrm{~L}$ sequence data. Plant Systematic and Evolution 211: 93-102.

Anderberg, A.A.; Stahl, B. \& Kallersjo, M. 2000. Maesaceae, a new primuloid family in the order Ericales s.1. Taxon 49:183-187.

Anderberg, A.A.; Rydin, C. \& Kallersjo, M. 2002. Phylogenetic relationships in the order Ericales s.l.: 
analyses of molecular data from five genes from the plastid and mitochondrial genomes. American Journal of Botany 89: 677-687.

Anderberg, A.A.; Manns, U. \& Kallersjo, M. 2007. Phylogeny and floral evolution of the Lysimachieae (Ericales, Myrsinaceae): evidence from ndhF sequence data. Willdenowia 37: 407-421.

APG (Angiosperm Phylogeny Group). 2003. An update of the Angiosperm Phylogeny Group classification for the orders and families of flowering plants: APG II. Botanical Journal of the Linnean Society 141: 399-436.

APG IV. 2016. An update of the Angiosperm Phylogeny Group classification for the orders and families of flowering plants: APG IV. Botanical Journal of the Linnean Society 181: 1-20.

BFG. 2015. Growing knowledge: an overview of seed plant diversity in Brazil. Rodriguésia 66: 1-29.

Caris, P.L. \& Smets, E.F. 2004. A floral ontogenetic study on the sister group relationship between the genus Samolus (Primulaceae) and the Theophrastaceae. American Journal of Botany 91: 627-643.

Carrijo, T.T. \& Freitas, M.F. 2008. Stylogyne (Myrsinaceae) do estado do Rio de Janeiro. Rodriguésia 59: 343-360.

Carrijo, T.T. \& Freitas, M.F. 2009. Stylogyne carautae (Myrsinaceae), a new species from south-eastern Brazil. Kew Bulletin 64: 695-699.

Carrijo, T.T.; Freitas, M.F. \& Peixoto, A.L. 2009. The identity and typification of Stylogyne laxiflora (Myrsinaceae). Nordic Journal of Botany 27: 1-3.

Carrijo, T.T.; Freitas, M.F. \& Peixoto, A.L. 2011a. A new species of Stylogyne (Myrsinaceae) from the Atlantic Forest of Brazil. Brittonia (Bronx, N.Y.) 63: 276-280.

Carrijo, T.T.; Silva-Fourny, A.C.; Freitas, M.F.; Gonçalves-Esteves, V.L. \& Peixoto, A.L. 2011 b. Insights on Ardisia and Stylogyne (Myrsinoideae - Primulaceae) based on pollen morphology. Plant Systematics and Evolution 297: 261-269.

Carrijo, T.T.; Freitas, M. F. \& Peixoto, A.L. 2012. The genus Stylogyne (Myrsinoidea -Primulaceae) in Brazil. Systematic Botany 37: 478-489.

Cronquist, A. 1981. An integrated system of classification of flowering plants. Columbia University Press, New York. 1262p.

Cronquist, A. 1988. The evolution and classification of flowering plants. $2^{\text {a }}$ ed. Columbia University Press. The New York Botanical Garden, New York. 1262p.

Daly, D.C. \& Silveira, M. 2008. Primeiro catálogo da Flora do Acre, Brasil. Editora da Universidade Federal do Acre, Rio Branco. 555p.

Freitas, M.F. \& Carrijo, T.T. 2008. A família Myrsinaceae nos contrafortes do Maciço da Tijuca e entorno do Jardim Botânico do Rio de Janeiro. Rodriguésia 59: 813-28.
Freitas, M.F.; Carrijo, T.T.; São-Leão, L.C. \& Kinoshita, L.S. 2009. Flora da Serra do Cipó, Minas Gerais: Myrsinaceae. Boletim do Instituto de Botânica (São Paulo) 27: 259-267.

Freitas, M.F. \& Kinoshita, L.S. 2015. Myrsine (Myrsinoideae- Primulaceae) no sudeste e sul do Brasil. Rodriguésia 66: 167-189.

Freitas, M.F.; Carrijo, T.T. \& Luna, B.N. 2016. Rediscovery of Cybianthus froelichii (Primulaceae), an endangered species from Brazil. Boletim do Museu de Biologia Melo Leitão 38: 31-38.

Garcia R.J.F. \& Izumisawa, C.M. 2003. Flora Fanerogâmica da Ilha do Cardoso (São Paulo, Brasil): Primulaceae. In: Wanderley, M.G.L.; Shepherd, G.J.; Giulietti, A.M. \& Melhem, T.S. (ed.). Flora Fanerogâmica do Estado de São Paulo. RiMa, São Paulo. Vol. 3, pp. 275-278.

Harvey, Y.B. \& Pipoly, J.J. 1995. Myrsinaceae. In: Stannard, B. (ed.). Flora of the Pico das Almas, Chapada Diamantina, Bahia, Brazil. Royal Botanic Garden, Kew. Pp. 487-491.

Judd, W.S.; Campbell, C.S.; Kellogg, E.A.; Stevens, P.F. \& Donoghue, M.J. 2009. Sistemática vegetal: um enfoque filogenético. $3^{\text {a }}$ ed. Artmed, Porto Alegre. 612p.

Joly, A.B. \& Jung, S.L. 1978. Cybianthus coronatus Joly et Jung sp.n. (Myrsinaceae): uma nova espécie da Serra do Cipó, Minas Gerais, Brasil. Hoehnea 7: 41-46.

Jung, S.L. 1981. Flora Fanerogâmica da Reserva do Parque Estadual das Fontes do Ipiranga (São Paulo, Brasil): Myrsinaceae. Hoehnea 9: 88-91.

Jung-Mendaçolli, S.L. 2009. Myrsinaceae. In: Cavalcanti, T.B. \& Batista, M.F. Flora do Distrito Federal, Brasil. Vol. 7. Embrapa Recursos Genéticos e Biotecnologia, Brasília. Pp. 229-247.

Jung-Mendaçolli, S.L. \& Bernacci, L.C. 1997. Flora Fanerogâmica da Ilha do Cardoso (São Paulo, Brasil): Myrsinaceae. In: Melo, M.M.R.F.; Barros, F.; Chiea, S.A.C.; Kirizawa, M.; JungMendaçolli, S.L. \& Wanderley, M.G.L. (ed.). Flora Fanerogâmica da Ilha do Cardoso. Vol. 5. Imprensa Oficial, São Paulo. Pp. 81-98.

Jung-Mendaçolli, S.L. \& Bernacci, L.C. 2001. Myrsinaceae da APA de Cairuçu, Parati (Rio de Janeiro, Brasil). Rodriguésia 52: 49-64.

Jung-Mendaçolli, S.L. \& Bernacci, L.C. \& Freitas, M.F. 2005. Myrsinaceae. In: Wanderley, M.G.L.; Shepherd, G.J.; Melhem, T.S.; Martins, S.E.; Kirizawa, M. \& Giulietti, A.M. (ed.). Flora Fanerogâmica do Estado de São Paulo. RiMa, São Paulo. Vol. 4, pp. 279-300.

Jung-Mendaçolli, S.L.; Bernacci, L.C. \& Freitas, M.F. 2010. Nova espécie de Cybianthus Mart. (Myrsinaceae) do sudeste do Brasil. Acta Botanica Brasilica. 24: 671-673. 
Kallersjo, M.; Bergqvist, G. \& Anderberg,A.A. 2000. Generic realignment in primuloid families of the Ericales s.1.: a phylogenetic analysis based on DNA sequences from three chloroplast genes and morphology. American Journal of Botany 87:1325-1341.

Lindeman, J.C. 1979. Theophrastaceae. In: Stoffers, A.L. \& Lindemann, J.C. (eds). Flora of Suriname 5: 367-369.

Lundell, C.L. 1982. Neotropical Myrsinaceae VII. Wrightia 7: 38-49.

Manns, U. \& Anderberg, A.A. 2005. Molecular phylogeny of Anagallis (Myrsinaceae) based on ITS, trnL-F, and $n d h \mathrm{~F}$ sequence data. International Journal of Plant Sciences 166:1019-1028.

Manns, U. \& Anderberg, A.A. 2007. Character evolution in Anagallis (Myrsinaceae) inferred from morphological and molecular data. Systematic Botany 32: 166-179.

Manns, U. \& Anderberg, A.A. 2009. New combinations and names in Lysimachia (Myrsinaceae) for species of Anagallis, Pelltiera and Trientalis. Willdenovwia 39: 39-54.

Mez, C. 1902. Myrsinaceae. In: Engler, H.G.A. Das Pflanzenreich. Berlin, Wilhelm Engelmann, 9: 1-437.

Miquel, F.A.G. 1856. Myrsineae. In: Martius, C.F.P.; Eichler, A.G. \& Urban, I. Flora Brasiliensis. : Typografia Regia, Munchen, Wien, Leipzig. Vol. 10, pp. 269-338, est. 24-59.

Mizushina, Y.; Miyazaki, S.; Ohta, K.; Hirota, M. \& Sakaguchi, K. 2000. Novel anti-inflammatory compounds from Myrsine seguinii, terpeno-benzoic acids, are inhibitors of mammalian DNA polymerase. Biochim. Biophys. Acta General Subjects 1475: 1-4.

Pipoly, J.J. 1981. Contributions toward a monograph of Cybianthus (Myrsinaceae): I. Subgenus Iteoides and the identity of Conomorpha loretensis. Brittonia 33: 493-497.

Pipoly, J.J. 1983a. Contributions toward a monograph of Cybianthus (Myrsinaceae): III. A revision of subgenus Laxiflorus. Brittonia 35: 61-80.

Pipoly, J.J. 1983b. Contributions toward a monograph of Cybianthus (Myrsinaceae): IV. Notes on subgenera Stapfia and Microconomorpha. Wrightia 7: 235-244.

Pipoly, J.J. 1987. A systematic revision of the genus Cybiantus subgenus Grammadenia (Myrsinaceae). Memoirs of the New York Botanical Garden 43: 1-76.

Pipoly, J.J. 1991. New species of Cybianthus subgenus Conomorpha from Amazonian Peru. Candollea 46: 41-45.

Pipoly, J.J. 1992. The genus Cybianthus subgnus Conomorpha (Myrsinaceae) in Guyana. Annals of the Missouri Botanical Garden 79: 908-957.

Pipoly, J.J. 1993. Notes on Cybianthus subgenus Cybianthus (Myrsinaceae) in southeastern Brazil. Novon 3: 459-462.
Pipoly, J.J. 1999. Myrsinaceae. In: Ribeiro, J.E.L.S.; Hopkins, M.J.G.; Vicentini, A.; Sothers, C.A.; Costa, M.A.S.; Brito, J.M.; Souza, M.A.D.; Martins, L.H.; Lohmann, L.G.; Assunção, P.A.; Pereira, E.C.; Silva, C.F.; Mesquita, M.R. \& Procópio, L.C. (eds.), Flora da Reserva Ducke. Guia de identificação das plantas vasculares de uma floresta de terra-firme na Amazônia Central. INPA-DFID, Manaus. Pp. 337-339.

Pipoly, J.J. 2008. Myrsinaceae. In: Daly, D.C. \& Silveira, M. Primeiro Catálogo da Flora do Acre, Brasil. Ed. Universidade Federal doAcre, Rio Branco. Pp. 276-277.

Pipoly, J.J. \& Ricketson, J.M. 2006. New species of Cybianthus Martius (Myrsinaceae) from the Hylean/ Andean Interface of Peru. Novon 16: 248-253.

Ricketson, J.M. \& Pipoly, J.J. 1997a. A synopsis of the genus Gentlea (Myrsinaceae) and a key to the genera of Myrsinaceae in Mesoamerica. Sida 17: 697-707.

Ricketson, J.M. \& Pipoly, J.J. 1997b. Nomenclatural notes and synopsis of the genus Myrsine (Myrsinaceae) in Mesoamerica. Sida 17: 579-589.

Souza, V.C. \& Lorenzi, H. 2008. Botânica Sistemática: guia ilustrado para identificação das famílias fanerogâmicas nativas e exóticas no Brasil, baseado em APG III. $3^{\text {a }}$ ed. Instituto Plantarum, São Paulo. 768p.

Stahl, B. 1991. A revision of Clavija (Theophrastaceae). Opera Botanica 107: 1-77.

Stahl, B. 2004a. Samolaceae. In: Kubtzki, K. (ed). The families and genera of vascular plants, VI. Flowering Plants Dicotyledons. Celastrales, Oxalidales, Rosales, Cornales, Ericales. Springer, Berlin. Pp. 387-389.

Stahl, B. 2004b. Theophrastaceae. In: Kubtzki, K. (ed). The families and genera of vascular plants, VI. Flowering Plants Dicotyledons. Celastrales, Oxalidales, Rosales, Cornales, Ericales. Springer, Berlin. Pp. 472-478.

Stahl, B. \& Anderberg, A.A. 2004. Myrsinaceae. In: Kubtzki, K. (ed). The families and genera of vascular plants, VI. Flowering Plants Dicotyledons. Celastrales, Oxalidales, Rosales, Cornales, Ericales. Springer, Berlin. Pp. 266-281.

Stevens, P.F. [2001 onwards]. Angiosperm Phylogeny Website. Version 12, July 2012 . Disponível em <http:// www.mobot.org/MOBOT/research/APweb/>. Acesso em 8 de dezembro de 2015.

Taylor, P. 1955. The genus Anagallis in tropical and South Africa. Kew Bulletin 3: 321-350.

Thiers, B. [continuously updated]. Index Herbariorum: a global directory of public herbaria and associated staff. New York Botanical Garden's Virtual Herbarium. Disponível em $<\mathrm{http}$ //sweetgum.nybg.org/science/ih/>. Acesso em 8 de dezembro de 2015.

Wanntorp, L. \& Anderberg, A.A. 2011. Evolution and diversification of brook weeds (Samolus, Samolaceae, Ericales). International Journal of Plant Science 172: 250-266. 